\title{
ATTITUDES OF FOURTH GRADE GYMNASIUM STUDENTS WHO ARE NOT IN MATHEMATICS AND INFORMATICS COURSE IN TERMS OF DESCRIPTIVE GEOMETRY AS A POSSIBLE COMMON SUBJECT IN ALL DIRECTIONS OF GYMNASIUM
}

\section{Original scientific paper}

\section{Tarik Bazdalić}

Alma Sehanovic

Sead Rešić ${ }^{1}$

Amila Osmić

Faculty of Education, University of Travnik, Bosnia and Herzegovina

Department of Mathematics, Faculty of Science, University of Tuzla, Bosnia and Herzegovina

Gymnasium "Meša Selimovič" Tuzla, Bosnia and Herzegovina

Secondary School of Civil Engineering and Geodesy Tuzla, Bosnia and Herzegovina

Received: 6/24/2020

Accepted: 8/26/2020

\begin{abstract}
Gymnasium as a school and as one of the levels in education has changed for decades both in the curriculum and in its duration. Nevertheless, the common goal in each period of Gymnasium education was and remains to provide students with the widest possible general education and to prepare them for further education at various universities of technical, social and natural sciences. In the last stage of socialism in Bosnia and Herzegovina, all high schools in their curriculum aimed to train students for one of the working professions so that each student after graduating from high school acquired a certain knowledge and could be employed in the sector for which educated. During that period, grammar schools were formally abolished. Instead, secondary administrative schools were most often formed, which were most similar to Gymnasiumin terms of their curriculum. In the present age, the gymnasium as a school exists with the fact that the curriculum is common to all first and second grades, while the third and fourth grades are divided into directions: mathematics-informatics, natural, social, linguistic and information-communication. Without going into the purpose of the existence of other directions, it should be emphasized that the mathematics-informatics direction aims to bring the students of the final grades of grammar school closer to technical and informatics universities, ie to
\end{abstract}

${ }^{1}$ Correspondence to:

Sead Rešić, Department of Mathematics, Faculty of Science, University of Tuzla, Bosnia and Herzegovina

Univerzitetska 4, 75000 Tuzla, Bosnia and Herzegovina

Phone:+38761 101230

E-mail: sresic@hotmail.com 
acquaint them with technical and informatics. One of the key subjects at some technical colleges is descriptive geometry. These would primarily be the universities of architecture, civil engineering and mechanical engineering. In informal conversations between fourth graders regardless of direction and their teachers from time to time the topic is the subject of descriptive geometry. From the mentioned conversations, two mutually opposing hypotheses crystallized in terms of the importance of descriptive geometry, ie whether or not descriptive geometry should be introduced in all directions of Gymnasium. In order to determine which of these two hypotheses prevails, a generic / developmental method was applied, ie a survey was used as one of the research techniques. The survey was conducted in February 2020. A sample of 80 fourth-grade students from the „Muhsin Rizvić“ Gymnasium in Kakanj and the „Visoko" Gymnasium in Visoko, who are not in the mathematics and computer science trend, was selected for the survey. As can be seen, the importance of descriptive geometry as a subject will be expressed by those students who do not have descriptive geometry as a subject according to the curriculum.

Key words: general education, school material, descriptive geometry, orientation, space, technical universities.

\section{PROBLEM AND SUBJECT OF RESEARCH}

Although the current gymnasiums in the third and fourth grade are divided by directions, there is still the possibility that students can enroll in any university after graduating from the gymnasium, regardless of which direction they completed the gymnasium. This means that the current Gymnasium, regardless of the direction, must train students to enroll in any of the universities. It is for this reason that perhaps some of the subjects that are only in one direction of the gymnasiumshould be extended to all other directions. In this particular case, it is the subject of descriptive geometry, ie whether the subject of descriptive geometry should be introduced as a common subject in the fourth grade of gymnasium in all directions.

"Contemporary thinking about teaching and educational process is within the theory of curricula (which we interpret as an organized arrangement of the learning process and content with regard to certain purposes and goals).

The long-term goals of the teaching process as an educational process are: to teach the student to think, to be creative, cultured, honest and self-aware, and independent in learning.

An individual subject, including descriptive geometry, can be understood as a polygon for achieving longterm goals. The teacher is a mediator, a moderator in a well-organized process" (Lipošinović, 2003).
Bearing in mind all the above, one can rightly think about the possibility of introducing the subject of descriptive geometry in the teaching of the fourth grade of gymnasiumin all directions. In that direction, we should first investigate the attitude of the students themselves about the mentioned possibility.

Therefore, the subject of this research is to check whether the students of the fourth grade of gymnasium would like to have the subject of descriptive geometry in class, even though they did not opt for the mathematical-informatics direction.

\section{AIM AND TASKS OF THE RESEARCH}

The main goal of this research is to determine whether fourth grade gymnasium students who have not opted for mathematics and computer science, are interested in introducing them to regular classes on the basics of descriptive geometry in which they would briefly acquire basic knowledge of descriptive geometry and technical drawing.

The research tasks derive from the subject of the research and the formulation of the goal:

1. To determine whether the students think that the knowledge they acquired in primary school in the subject of technical education is enough for them to be able to continue their education at one of the technical universities after gymnasium.

2. To determine whether students who are not in the 
mathematics and computer science department think that their knowledge of descriptive geometry and technical drawing would be good if they decided to enroll in one of the technical universities after graduating from gymnasium.

3. To determine whether the students think that their knowledge of descriptive geometry would contribute to the expansion of general culture since they did not opt for the mathematics and informatics direction.

\section{HYPOTHESES}

From the stated goal and tasks of the research, the null hypothesis is set first, which reads:

$\mathrm{H}_{0}$ : Fourth grade gymnasium students who did not opt for mathematics and computer science, believe that the knowledge of technical education they acquired in primary school is quite enough and that this knowledge is a good basis for them to continue their education at one of the technical universities. Their opinion is that the introduction of some new subjects in teaching that are not directly related to the direction they have chosen, is superfluous. It can only further burden the already difficult and extensive material of numerous subjects that are studied in gymnasium.

In contrast to the null hypothesis, the main research hypothesis follows:

H: Fourth grade gymnasium students who have not opted for mathematics and informatics, believe that the general technical knowledge they acquired in primary school is not enough and cannot be the basis for continuing their education at one of the technical universities. Therefore, they believe that the introduction of the subject of descriptive geometry in regular classes in all fourth grades of gymnasium, regardless of the direction, would be welcome. The introduction of such a subject in the regular classes of the gymnasium would also contribute to the expansion of general culture and education, which is otherwise a characteristic of the gymnasium itself.

\section{SAMPLE, RESEARCH ORGANIZATION AND STATISTICAL DATA PROCESSING}

In order to ensure the best possible conditions of the survey, while obtaining the most authoritative empirical data, the characteristics of the sample and its size were taken into account. The sample consisted of fourth grade students who are not in the mathematics and computer science department of the Gymnasium "Muhsin Rizvić" in Kakanj and the Gymnasium "Visoko" in Visoko. A total of 80 students took part in the survey. In general, this is a medium-sized sample, but in this case the number of respondents is not as important as the results of the research itself.

Given the purposefulness, quality and success of the survey, care was taken to ensure that the questionnaire was compiled to meet the appropriate requirements, which are:

- "that the respondents are highly motivated to answer the questions, ie that the survey is interesting to them with its content;

- to receive relevant information from the respondent that cannot be obtained in any other way;

- the questionnaire is not too long and that the filling does not require a lot of time;

- that the questionnaire has an aesthetic quality (arranged and reviewed);

- not to enter the intimate life of the respondents;

- that the anonymity of the respondents is guaranteed;

- that the questions are completely clear;

- that the questions are formulated briefly, unambiguously, understandably, without superfluous words, unusual and unknown terms and that the questions are not too grammatically complicated;

- that the questions are not of a suggestive nature. “(Selimović, Rodić \& Selimović, 2013.)

From the general data, each respondent had to enter the average grade in mathematics, department and gender on the questionnaire. 
The questionnaire was closed-ended and consisted of nine questions. Three possible answers were offered to each question. The answers were graded from one to three, but so that the way of scoring was not known to the respondents so that the questions would not be suggestive.

The offered answers scored with one point each were formulated in support of the null hypothesis. Those answers that were scored with two points each, indicate an equal outcome between the zero and the main hypothesis, and finally the answers scored with three points each were formulated in support of the main hypothesis.

The compiled questions for the questionnaire and possible answers with scoring are presented as follows:

1. Do you remember what you learned from the subject of technical education in primary school?

a) Yes. I remember just as much as the other subjects. (2)

b) What did not interest me did not remain in my memory. (1)

c) Yes. That subject was particularly interesting to me. (3)

2. Are you thinking of continuing your education at one of the technical universities, even though you did not choose the mathematics and informatics department at the Gymnasium?

a) Of course. That's what I intend to do. (3)

b) If I thought about it, I would not choose this direction in the Gymnasium. (1)

c) I don't think, but it is possible that it will happen. (2)

3 . If you would still enroll in one of the technical universities, do you think that the knowledge you acquired in primary school in the subject of technical education will be a good basis for continuing your education at that university?

a) I'm not sure. (2)

b) This knowledge can in no case be a good basis for continuing education at any of the technical universities. (3)

c) I think that the subject of technical education from primary school is a good basis for continuing education at one of the technical universities. (1)

4. Do you know, unlike you, that your colleagues in the fourth grade of the Gymnasium of Mathematics and Informatics, in addition to other subjects, have the subject of descriptive geometry?

a) I don't know. (1)

b) Yes, I learned that from a colleague recently. (2)

c) Yes, I know from before. (3)

5. Do you know what the subject of drawing geometry studies?

a) In that subject, one learns how to write technical letters and how to draw various geometric pictures and figures. (2)

b) From this subject, one learns how to technically present various objects in space. (3)

c) I don't know. (1)

6. If the subject of descriptive geometry were common to all directions in the Gymnasium, do you think that knowledge from that subject would be good for you in case you still decide to continue your education at one of the technical universities?

a) Of course. (3)

b) However, one should also think of those students who would never enroll in one of the technical universities and would not even want to have the subject of descriptive geometry in the Gymnasium. (1)

c) I didn't think about it. (2)

7. Do you think that knowledge of descriptive geometry would contribute to a better perception of objects around you?
a) No (1)
b) Yes (3)
c) I didn't think about it. (2)

8. If you possessed a basic knowledge of descriptive geometry and technical drawing, do you believe you could understand some simpler technical drawings?

a) I think in that case I could understand simpler technical drawings. (2)

b) I have no idea. (1)

c) I believe that in that case with a little more interest I could understand some simpler technical drawings. (3) 9. Do you think that your knowledge of descriptive geometry would contribute to the expansion of general education and culture in the event that this subject is common to all directions in the Gymnasium? 
a) I think that the introduction of descriptive geometry in all directions in the Gymnasium would be superfluous. (1)

b) Certainly, my knowledge of descriptive geometry would enrich my general education, which I normally acquire in Gymnasium. (3)

c) Maybe. (2)

The scoring of the offered answers to the given questions from the questionnaire is made so that the sum of points of the completed questionnaire cannot be less than 9 or more than 27. From the stated range of possible sum of points of the completed questionnaire a scale is made groups as follows:

\section{1. group $\rightarrow 9-16$ points}

This group includes those respondents who are against descriptive geometry being a common subject in all directions in the Gymnasium.

2. group $\rightarrow \rightarrow 17-20$ points

This group includes those respondents who are undecided on the issue of descriptive geometry being a common subject in all directions in the Gymnasium.

3. grupa $\rightarrow \rightarrow 21-27$ points

This group includes those respondents who would like the descriptive geometry to be a common subject in all directions in the Gymnasium.

\section{RESULTS}

When processing and interpreting the test results, the percentage procedure was used as the fastest and simplest type of statistical processing.

Therefore, after conducting a survey on a sample of a total of 80 fourth-grade students who are not in mathematics and computer science at Gymnasium "Muhsin Rizvić" in Kakanj and Gymnasium "Visoko" in Visoko and reviewing and processing the questionnaire, the results are shown in summary Table 1 and Graph 1.

Table 1.

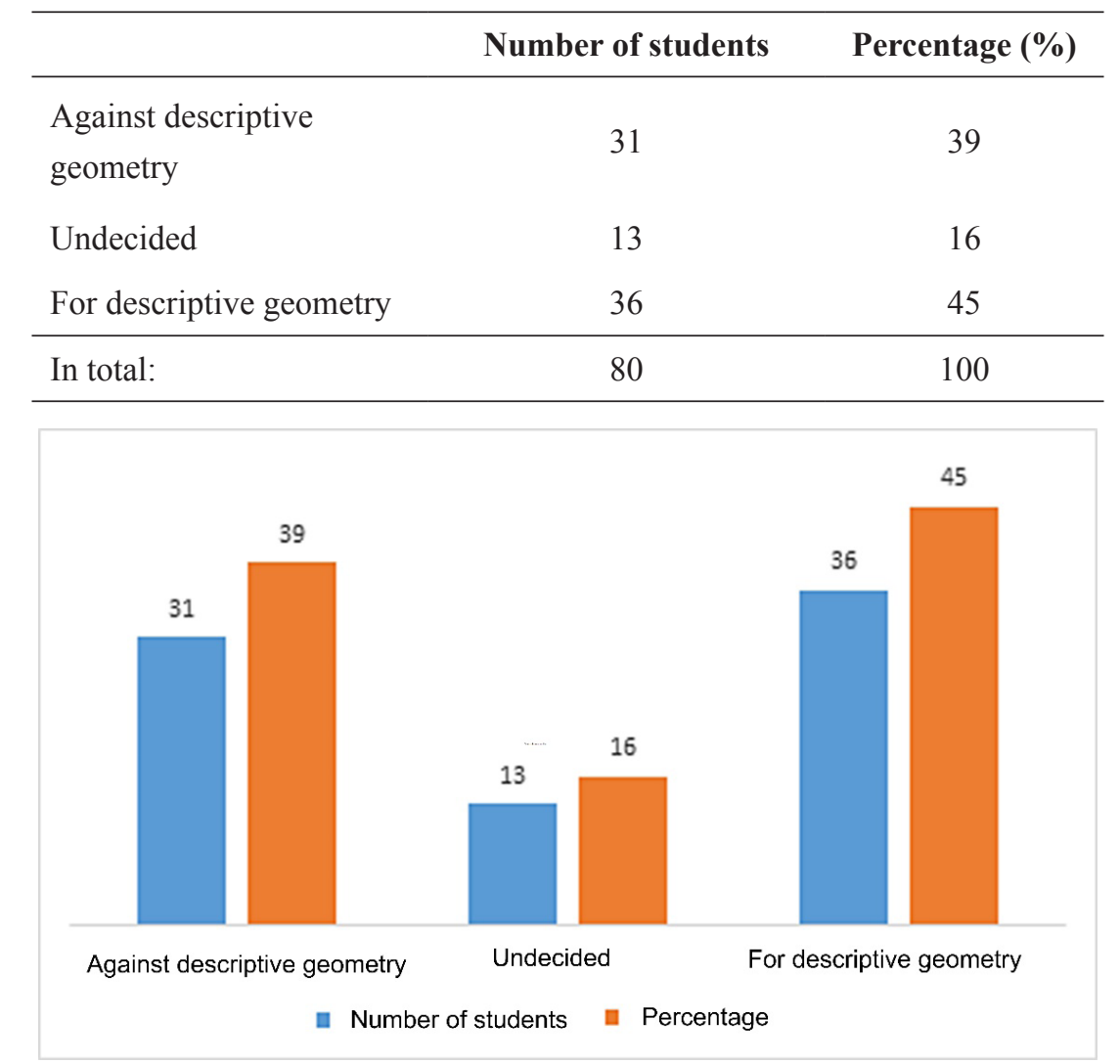

Graph 1. 
The response structure of the conducted survey is shown in Table 2 and Graph 2.

Table 2. The response structure of the conducted survey

$\begin{array}{ccccc} & \text { In support of the null } & \text { Undecided } & \text { In support of the main } \\ \text { hypothesis } & \text { hypothesis }\end{array}$

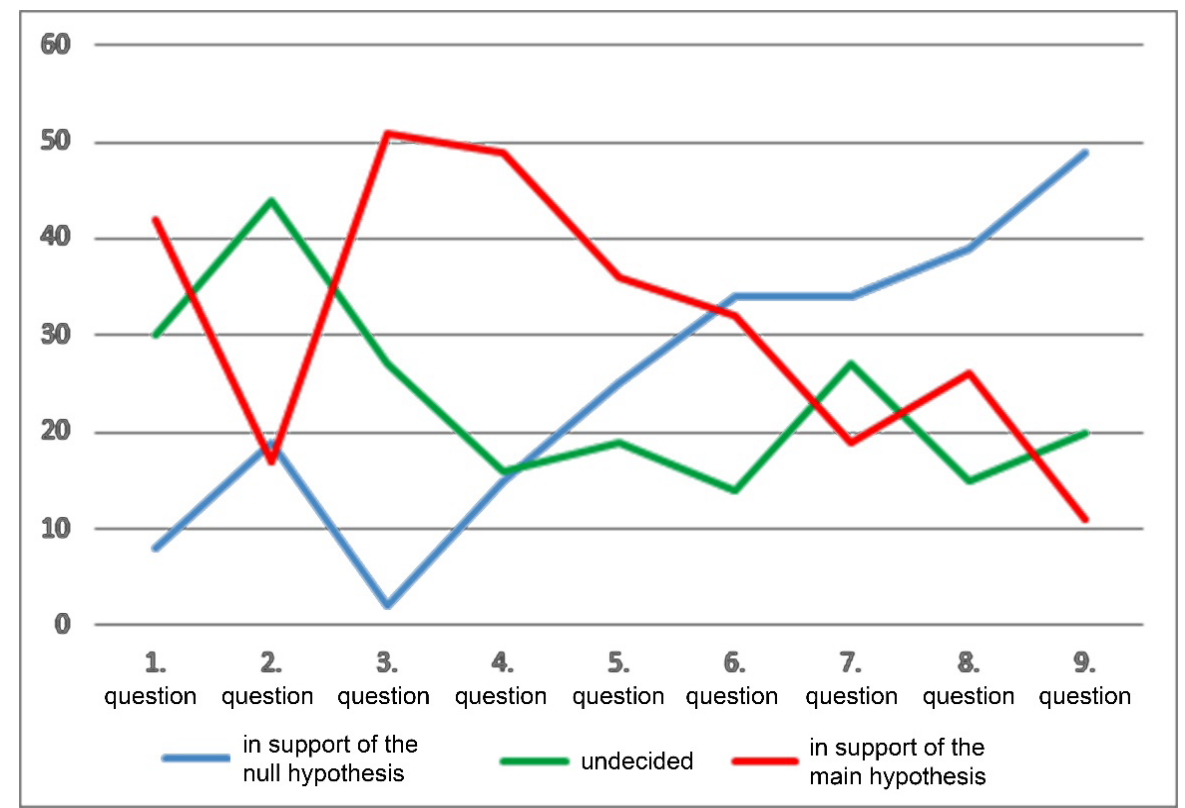

Graph 2. The response structure of the conducted survey

\section{CONCLUSION}

Based on the obtained research results, it can be formally concluded that according to previously determined criteria, $39 \%$ or approximately $8 / 20$ of the representative sample are those respondents who are against descriptive geometry being a common subject in all directions in the Gymnasium.

At the same time, $16 \%$ of the representative sample, or approximately $3 / 20$, are those respondents who are undecided that the descriptive geometry should be a common subject for all directions in the Gymnasium. And finally, $45 \%$ of the representative sample, or approximately $9 / 20$, are those respondents who would like the descriptive geometry to be a common subject for all directions in the Gymnasium.
According to the obtained research results, the main hypothesis was formally confirmed.

However, these results should be taken with a grain of salt for the following reasons:

There is very little difference between the number of respondents who completed the questionnaire in support of the null hypothesis and the number of respondents who completed the questionnaire in support of the main hypothesis (only 5 respondents or 6\%).

If we look at the structure of the answers of the survey, to the questions that directly mention the introduction of descriptive geometry for all students of the Gymnasium, regardless of the direction, a larger number of respondents gave answers in favor of the null hypothesis. These are the answers to questions 6 ; 7; 8 and 9. 
Thus, despite the formally obtained results in support of the main hypothesis based on the given assumptions, it is still not possible to discuss that descriptive geometry should be a common subject for all Gymnasium students regardless of direction.

\section{REFERENCES}

Justinijanović, J. (1965). Nacrtna geometrija za I razred građevinskih škola [Descriptive geometry for the first grade of construction schools]. Zagreb, Croatia: Školska knjiga.

Lipošinović, L. (2003). Priručnik za nastavnike uz udžbenik nacrtna gometrija [Teachers' manual with tutorials Descriptive Geometry]. Zagreb, Croatia: Element.

Selimović, H., Rodić, N., \& Selimović, N. (2013). Metodologija istraživanja [Research methodology]. Travnik, Bosnia and Herzegovina: University of Travnik, Faculty of Education. 